\title{
A AÇÃO DOCENTE NA EDUCAÇÃO INFANTIL À LUZ DA CORPOREIDADE
}

\author{
Madma Laine Colares Gualberto(*) \\ Hergos Ritor Fróes de Couto ${ }^{(* *)}$
}

O homem é produto da evolução histórica e cultural do mundo. Nesse processo, o corpo do ser humano passou por mudanças e adaptações em todas as dimensões, sejam estas biológicas, intelectuais, afetivas, morais e sociais. Com o passar dos tempos, o homem apropriou-se das palavras e de suas significações, criando novas aptidões e funções psíquicas para viver em sociedade.

Conforme cita Leontiev (1978, p. 07), “o movimento da história só é, portanto, possível com a transmissão, às novas gerações, das aquisições da cultura humana, isto é, com a educação". Entretanto, a educação vem sendo utilizada como uma ferramenta de controle dos corpos para uma sociabilidade desejada:

A educação tem sempre a referência e seu campo de atuação no corpo, seja para moldá-lo a uma configuração da sociedade na qual ele é um instrumento de garantia de seu funcionamento, seja para reprimi-lo nos seus impulsos atávicos, seja ainda para marcá-lo com sinais inequívocos nos rituais de passagem com o propósito de lembrá-lo de que pertence a um grupo, a uma comunidade (INFORSATO, 2006, p. 92).

$\mathrm{Na}$ abrangência de entendimento sobre a evolução gradual do homem, o corpo sempre esteve dominado pelos interesses da sociedade. Os corpos ainda estão aprisionados a uma educação hierarquizada, reprimido por esquemas disciplinares nas instituições educacionais, as quais desconsideram as linguagens e códigos, a flexibilidade, as interações com o outro, a liberdade e a autonomia dos seres humanos enquanto sujeitos do próprio processo de produção do conhecimento (LEONTIEV, 1978).

Na perspectiva de uma educação que liberte o corpo ao invés de dominá-lo, que transcenda ao pensamento dicotômico de corpo-alma, que perceba o ser humano em sua complexidade, é que se torna importante compreender a corporeidade. Para entendê-la é necessário quebrar alguns

\footnotetext{
${ }^{(*)}$ Mestre em Educação pela Universidade Federal do Oeste do Pará (UFOPA)(2017) Orcid: <https://orcid.org/00000001-7794-0269>.E-mail: madma.gualberto@ufopa.edu.br.

${ }^{(* *)}$ Doutor em Educação, professor efetivo da Universidade Federal do Oeste do Pará (UFOPA), na categoria Adjunto IV, atua principalmente nos campos de educação e corporeidade e educação e esporte. Orcid: <https://orcid.org/00000002-0101-4012>.E-mail: hergos@ hotmail.com.
} 
paradigmas culturais e históricos. A corporeidade implica em ter a capacidade de olhar o mundo e sentir-se parte dele como corpo vivo, atuante, comunicativo em processo constante de aprendizagem.

Considerar a corporeidade é buscar superar a visão cartesiana; uma maneira de relacionar a realidade sensível à realidade ideal, como mundos indissociáveis; um desafio, pois as concepções de corpo mudaram ao longo dos tempos; é uma proposta de refletir o ser-estar-no-mundo como exercício de uma vida autônoma e crítica; é complexo, pois o ser humano é múltiplo; é aprender a ouvir, sentir e agir; oportunizar o autoconhecimento para melhor percepção do outro; reconhecer que o homem se transforma; é uma tentativa de fazer-se melhor a cada dia para si e para o meio movimentando-se com o outro e com o mundo em uma relação multidimensional.

Diante dessas concepções, enfatiza-se que:

A compreensão da corporeidade somente será possível se aliarmos as definições e conceitos extraídos de manuais às observações, superando assim a visão do homem unidimensional, técnico, um ser separado, para uma visão em que o homem apareça como um ser imaginativo, sonhador, criador, aliando a sabedoria da técnica e da ciência à arte e à poesia, tendo como consequência um modelo existencializado e multidimensional de ser humano (INFORSATO; FIORANTE, 2010, p. 137).

Ser corporeidade é projetar um olhar sensível sobre o outro, escutando e respeitando-o, embora as concepções de mundo possam ser contrárias. Para entender essa visão, é imprescindível que o indivíduo se reconheça como um ser vivente em constante relação com o outro e com o mundo.

Nesse sentido, o corpo que se discute nesse estudo é o que se movimenta pelo tempo e espaço através de gestos, expressões, vozes, pensamentos, anseios, conhecimentos, sorrisos, vontades, sonhos, que é capaz de sentir dor, alegria, tristeza, carinho e afeto, tudo ao mesmo tempo.

Segundo Moreira et al.:

O conceito de corpo ativo [...] é o da corporeidade vivida, em que o ser pensa o mundo, o outro e a si mesmo na tentativa de conceber essas relações, na tentativa de reaprender a ver a vida e o mundo. O corpo ativo, que é vida, busca ver os seres que se mostram, pois estes estão escondidos uns atrás dos outros ou atrás de mim. O corpo ativo busca, em sua existencialidade, olhar os objetos, sabendo que isso demanda habitá-los e assim aprender ou incorporar as coisas nas mais diversas perspectivas (2006, p. 139). 
Deste modo, corpo ativo se remete à tentativa de estabelecer relações com os outros, com os objetos e com o mundo, na perspectiva de uma aprendizagem significativa, pois "educar-se é aprender a fazer história, fazendo cultura" (MOREIRA et al., 2006, p. 140). Além disso, os conhecimentos produzidos nas instituições de ensino devem considerar que o sujeito não aprende somente com uma parte do seu corpo, o homem não é constituído nem só da razão, nem tampouco só da emoção, mas da inter-relação dessas dimensões humanas. Nesse sentido, "o conhecimento não emana nem do polo concreto, representado pelo objeto (realidade), nem do polo abstrato, representado pelo sujeito (pensamento), concentrando-se no movimento entre estes polos" (ABRANTES; MARTINS, 2007, p. 315-316).

Nessa perspectiva, a corporeidade surge como uma abordagem importante na formação de professores, pois compreende que a educação é humanizadora e que a escola, por meio dos agentes educacionais, corrobora para o aprimoramento da aprendizagem e da internalização das qualidades humanas, tais como a solidariedade, ética, respeito, conhecimento de si e do outro.

A temática corporeidade nos processos formativos iniciais e continuados contribui para a reflexão em torno do pensamento de ser e estar no mundo; para melhor compreensão da referida expressão citam-se as palavras de Couto $(2008$, p. 7) "viver é ser é estar no mundo, meu corpo é ser é aqui estar, nas vias do meu ser caminho estando, sendo vida meu corpo aqui está". É por meio do corpo que o humano se expressa, sente, pensa, age e atribui significados no mundo vivido. Ainda segundo o autor, a aprendizagem é desenvolvida a partir das relações do corpo consigo, com o outro, com os seres, o que justifica a necessidade do indivíduo em se relacionar com o meio para explorar, aprender, identificar sentidos e produzir conhecimentos.

Abordar a corporeidade no processo educacional proporciona conhecer o fenômeno humano a partir do sentido da existência, da sensibilidade, da imaginação, das experiências teóricas e práticas e da aprendizagem significativa. No processo de humanização é preciso considerar que o corpo humano não é simplesmente um conjunto de órgãos, mas deve ser compreendido a partir de sua totalidade e complexidade existencial. Partindo desse princípio, o indivíduo é um sujeito que pensa o mundo e estabelece relações de prazer, felicidade, tristeza, medo e autossuperação (MOREIRA et al., 2006).

Por isso, o professor como sujeito motivador, crítico e transformador da formação integral dos educandos precisa ter a responsabilidade de refletir temáticas relacionadas ao corpo, uma vez que estão atreladas ao desenvolvimento humano, cultural e histórico. A tarefa de formar docentes é multidimensional, compreende as dimensões humanas, avaliativas, críticas e reflexivas. Ao 
professor cabe, portanto, a tarefa de buscar a emancipação e a consolidação de sujeitos autônomos, o papel deste profissional não deve ser visto como mecânico, fragmentado que se reflete em uma sociedade opressora na "cultura do silêncio".

Segundo Freire (2011) o que importa na formação docente não é uma repetição automatizada do movimento, mas sim a compreensão do valor dos sentimentos, dos desejos, das emoções e da superação dos desafios encontrados no cotidiano escolar. O papel do educador não é apenas ensinar os conteúdos, mas, também, ensinar a refletir corretamente. Daí a importância de desenvolver condições para constituir uma educação crítica e instigadora, visto que:

Nenhuma formação docente verdadeira pode fazer-se alheada, de um lado, do exercício da criticidade que implica a promoção da curiosidade ingênua à curiosidade epistemológica, do outro, sem o reconhecimento do valor das emoções, da sensibilidade, da afetividade, da intuição ou da adivinhação. Conhecer não é, de fato, adivinhar, mas tem algo que ver, de vez em quando com adivinhar, com intuir (FREIRE, 2011, p. 45-46).

Partindo desse pensamento, entende-se que o reconhecimento desses valores permite a apropriação de conhecimentos de si e do outro, assim o sujeito será capaz de conhecer-se corporalmente criando possibilidades para a formação humana. $\mathrm{O}$ autor reflete que o professor deve estar preparado para interpretar as indagações, curiosidades e gestos dos educandos.

Daí a importância deste profissional descontruir o pensamento mecanicista e dualista presente até hoje nas instituições de ensino, que implica na ideia de que o corpo e a mente são concebidos de maneira desarticulada. Predomina, ainda, o pensamento de que o conhecimento só pode ser produzido a partir da disciplina excessiva, da rigidez, da submissão do corpo estanque e passivo. Essas concepções dualistas apresentam-se nos ambientes escolares quanto nos sociais aos quais os sujeitos estão envolvidos, como por exemplo, a igreja e a família.

Diante desse cenário, percebe-se a necessidade de vivências corporais diversas nos cursos de formação inicial e continuada de professores, de forma a assegurar a compreensão dos valores humanos, a atribuição de sentidos e significados e o favorecimento da visão do indivíduo como um sujeito ativo no próprio processo de produção do conhecimento, que interage com o meio e se realiza a partir de sua corporeidade. 


\section{OS CAMINHOS PERCORRIDOS E OS PARTICIPANTES DA PESQUISA}

Nesse estudo, desenvolveu-se uma linha metodológica de caráter descritivo e campo, com uma abordagem qualitativa. Os instrumentos utilizados consistiram na observação não participante e realização de entrevistas semiestruturadas com os professores de educação infantil, elaboradas a partir de questões norteadoras que embasaram a temática.

Para análise dos dados foi utilizado o recurso da Análise de Conteúdo. Este tipo de análise, enquanto método de organização focaliza a qualificação de vivências do sujeito, assim como a percepção de determinados objetos e fenômenos (BARDIN, 2011). Segundo a autora, a análise de conteúdo busca descrever o conteúdo absorvido no processo da pesquisa, tanto por meio de falas quanto de textos.

A escolha deste recurso de análise é oriunda da necessidade de compreensão dos significados e entendimento das relações estabelecidas pela sistematização e interpretação das falas dos participantes da pesquisa. Segundo Minayo (2007), as etapas da análise de conteúdo são: Préanálise, Exploração do material ou codificação e Tratamento dos resultados obtidos/interpretação. A etapa de pré-análise compreende a constituição do corpus e a leitura exaustiva do material coletado em campo, o que pode contribuir para a formulação e reformulação das teorias relacionadas à temática do estudo. Ao término desta fase, o pesquisador formula os indicadores que embasarão a análise.

Para a definição da amostra, de forma que o estudo contemplasse uma visão da Educação Infantil em escolas públicas e particulares em Santarém-Pará, selecionou-se 08 professores e 04 escolas de educação infantil.

Sendo:

- 02 (dois) professores de escola de educação infantil particular central;

- 02 (dois) professores de escola de educação infantil pública central;

- 02 (dois) professores de escola de educação infantil particular periférica;

- 02 (dois) professores de escola de educação infantil pública periférica.

Cabe lembrar que, para o estudo, preservou-se a identidade dos participantes e da instituição, visando garantir o anonimato e o respeito aos participantes da pesquisa. Portanto, as professoras e as instituições de educação infantil foram identificadas pelas seguintes nomenclaturas:

P1PARTC - Professora de Escola Particular Central PEPRP1

P2PARTC - Professora de Escola Particular Central 


\section{P3PUBLC - Professora de Escola Pública Central \\ P4PUBLC - Professora de Escola Pública Central \\ P5PARTP - Professora de Escola Particular Periférica \\ P6PARTP - Professora de Escola Particular Periférica \\ P7PUBLP - Professora de Escola Pública Periférica \\ P8PUBLP - Professora de Escola Pública Periférica}

Os critérios de inclusão dos participantes para a pesquisa de campo consideraram o interesse em participar da pesquisa, concordando em assinar o Termo de Consentimento Livre e Esclarecido (TCLE), bem como, docentes que tivessem formação em Pedagogia e ministrassem atividades na educação infantil para a pré-escola.

Nessa conjuntura, justifica-se a escolha por professores da pré-escola em razão desta fase se aproximar mais do ingresso das crianças no processo de escolarização, por meio do ensino fundamental. Cabe destacar que os profissionais da educação infantil podem possibilitar a aproximação da escrita e da leitura ao universo infantil, no entanto, deve-se evitar a exaustão precoce em função da realização de atividades mecânicas e repetitivas, que causem um aprendizado sem significado, e ainda a insatisfação e a domesticação das crianças.

As crianças da pré-escola estão cada vez mais condicionadas a realizarem atividades preparatórias para o ensino fundamental. O uso de exercícios, em materiais impressos, o controle do professor para que a criança fique sentada e concentrada para a efetivação do "dever" demonstram uma possível problemática no que se refere à compreensão de corporeidade na primeira etapa da educação básica.

Justifica-se a escolha por professores com formação em Pedagogia, pois se acredita que os participantes apresentam conhecimentos mais apropriados da corporeidade e educação infantil.

Optou-se em investigar duas redes de ensino, pública e privada, sendo 02 centrais e 02 periféricas do município de Santarém, somando-se, então, 04 escolas, por pertencerem a contextos estruturais e formativos diferenciados, fato que introduz elementos sociais, curriculares e pedagógicos que, possivelmente, influenciam nas compreensões de corporeidade das participantes da pesquisa.

Destaca-se, ainda, que se escolheu o quantitativo de 04 escolas, porque dentro deste cenário percebeu-se a possibilidade de examinar adequadamente a temática do estudo, sem comprometer a qualidade da investigação, além de se tratar de instituições de educação infantil de referência de ensino em Santarém, PA. 


\section{ANÁLISE DOS DADOS}

A existência humana funda-se no corpóreo, portanto não existe aprendizagem sem passar pelo corpo. Dentro e fora da sala de atividades devem existir práticas docentes que ultrapassem a dimensão cognitiva e intelectual, que considerem e proporcionem experiências e vivências às crianças, enquanto sujeitos de direitos, históricos, complexos e culturais no mundo (MERLEAUPONTY, 1999).

Neste sentido,

a Corporeidade nos fundamentos da prática docente, implicada na formação humana, indica que os professores devem estimular o desenvolvimento de uma postura autônoma e crítica de ser e estar no mundo dos alunos, que reflita diretamente na maneira de aprender e de apreender conhecimentos/saberes desenvolvidos no ensino fundamental das séries iniciais dos territórios rurais, que possa ajudá-los no enfrentamento dos desafios da sociedade (RODRIGUES, 2018, p. 52).

Considerando que a escola deve promover o processo de formação humana por meio da sua manifestação mais acentuada, a saber, o movimento, este necessita ser ressignificado no âmbito das práticas docentes, pois "a educação envolve todo esse instrumental de formas de percepção do mundo, da comunicação e de intercomunicação e de autoconhecimento das necessidades humanas" (RODRIGUES, 2001, p. 243).

Ao se perguntar sobre as práticas docentes desenvolvidas pelas professoras de educação infantil que se relacionam com a temática do corpo/corporeidade, destacaram-se as falas de duas professoras por apontarem a necessidade das crianças interagirem com os espaços da escola. Vale salientar que se optou por extrair apenas as ideias centrais contidas nas respostas das professoras, conforme atestam os depoimentos a seguir.

[...] se for para contar histórias sobre a natureza, a paisagem, a gente traz eles para fazer um passeio pela escola. [...] não gosto de ficar muito presa em sala de aula [...] com o jardim sinto mais correria [...] tem toda essa rotina para ser seguida [...] eles ficam agitados, quando passam muito tempo em sala (P1PARTC).

[...] músicas coreografadas, as brincadeiras em sala de aula e fora da sala também. Sempre as atividades propostas [...] tem uma atividade de movimento [...] tem a música, a brincadeira, algo que tire eles da cadeira, não só aquela coisa do registro, então tem as dramatizações, as brincadeiras, onde eles correm, onde eles tem que fazer determinados movimentos ao meu pedido (P6PARTP). 
Observa-se que as professoras P1PARTC e P6PARTP apresentam uma percepção quanto à necessidade de diversificar as atividades propostas em outro espaço da escola, de forma que a criança não permaneça o tempo todo sentada na cadeira, realizando as tarefas de registro do livro didático. A professora P1PARTC relata que as próprias crianças se incomodam e se agitam quando ficam muito tempo na sala de atividades.

Este fato evidencia que a criança precisa se movimentar, conviver, conhecer e estar na presença de outras pessoas, objetos e ambientes. Percebe-se que ambas as professoras associam as práticas docentes relacionadas à corporeidade com o movimento e as atividades realizadas pautamse em brincadeiras e músicas. Assim, as profissionais entendem que as crianças vivenciam momentos importantes de aprendizado nos mais variados espaços da escola.

Neste viés, a Base Nacional Comum Curricular (BNCC), mais especificamente o campo de experiência intitulado "corpo, gestos e movimentos" ressalta que as crianças, por meio do deslocamento, do jogo, das brincadeiras, do tato, dos sentidos em geral, expressam-se, experimentam sensações e usufruem de espaços e neles se relacionam, construindo conhecimentos de si, do outro e do mundo.

Merleau-Ponty (1999) observa o corpo como criador de sentidos, uma vez que a percepção é um acontecimento da corporeidade, isto é, da existência humana, a qual se realiza também por meio da intencionalidade dos movimentos. Dessa forma, as sensações, as emoções, expressões e à realização de gestos estão associadas.

É importante mencionar que a aprendizagem passa pelas relações corporais, pela interação professora-criança e criança-criança, possibilitando o desenvolvimento de potencialidades, de forma que a criança compreenda o significado das coisas. Todavia, é indispensável que a professora seja mediadora dessa aprendizagem. Nesse sentido, a docente por meio de atitudes reflexivas deve estimular a criança a compreender o seu próprio movimento, a sua corporeidade. Isso só será possível por meio das experiências vividas consigo, com o outro e com o mundo (PROSCÊNCIO, 2010).

Cabe então reconhecer que a corporeidade pode ser inserida nas práticas docentes dos professores de educação infantil, de forma a contribuir para que estes profissionais reconheçam a si e aos outros como corpos autônomos, criativos, complexos e dinâmicos.

Nessa perspectiva, os pressupostos da temática da corporeidade, presentes nas práticas docentes, contribuem para reflexões acerca do ser humano que expressa emoções, sente, chora, cria, 
imagina, sorri, vibra, grita, aprende, erra, acerta, age, retroage, transcende, supera obstáculos, pensa e atribui significados a partir das relações corporais estabelecidas.

Quanto às outras professoras participantes desta pesquisa, ao discorrerem acerca deste assunto, destacam que desenvolvem práticas docentes relacionadas às (ao, à):

[...] brincadeiras, jogos ao ar livre, brincadeiras de correr, equilíbrio (P2PARTC).

[...] pular, correr, brincadeira (P3PUBLC).

Música [...] e brincadeiras livres (P4PUBLC).

[...] brincadeiras, mas na verdade a maior parte acontece na parte de música, [...] nas atividades que nós realizamos de conteúdos que não fazem parte de música, ou fazem partes de atividades de arte, nós trabalhamos muito o corpo também (P5PARTP).

Brincadeiras, músicas [...] (P7PUBLP).

Dança [...], música, eu gosto muito de cantar, quase todos os dias eu canto com eles, e a gente faz gestos (P8PUBLP).

As professoras P2PARTC, P3PUBLC, P4PUBLC, P5PARTP, P7PUBLP e P8PUBLP são bem diretas em suas respostas e afirmam que desenvolvem práticas voltadas à realização de brincadeiras livres, música e dança. De maneira geral, as professoras supramencionadas, também associam as práticas docentes à corporeidade com o movimento.

Segundo Borba (2007), a experiência do brincar não é simplesmente reproduzida, mas recriada a partir do que a criança carrega de novo, com o seu poder de imaginar, sentir, pensar e produzir cultura. A brincadeira é uma atividade que identifica os sujeitos em diferentes tempos e espaços, bem como, é uma ação de interação com as outras pessoas, com os objetos, lugares e com a natureza. Por meio do brincar, as crianças apropriam-se criativamente de práticas sociais específicas da população a qual pertence, compreendendo sobre si e sobre o mundo ao seu redor.

Nesse sentido,

Se entendermos que a infância é um período em que o ser humano está se constituindo culturalmente, a brincadeira assume importância fundamental como forma de participação social e como atividade que possibilita a apropriação, a ressignificação e a reelaboração da cultura pelas crianças (BORBA, 2007, p. 12).

Segundo a autora, a brincadeira é um fenômeno da cultura, pois se configura em um conjunto de práticas e conhecimentos acumulados pelo ser humano nos contextos históricos e sociais aos quais se inserem, representando um processo interativo e reflexivo, capaz de ampliar e potencializar os conhecimentos das crianças. Daí a importância da realização de práticas docentes 
que contemplem o brincar neste universo, oportunizando aos sujeitos momentos relevantes para a aprendizagem e formação do ser.

De acordo com as Diretrizes Curriculares Nacionais da Educação Infantil (DCNEI), as práticas docentes devem ser norteadas por dois eixos: as interações e brincadeiras, garantindo experiências que proporcionem o conhecimento de si, do outro e do mundo, por meio de vivências sensoriais, expressivas e corporais. Orienta que os professores devem favorecer o contato das crianças às diversas formas de expressão, tais como gestuais, verbais, dramáticas e musicais. Além disso, as atividades desenvolvidas devem recriar contextos significativos às crianças, ampliando a curiosidade, exploração e o conhecimento dos infantes em relação ao mundo, promovendo, ainda, a interação com diversas manifestações de artes, cinema, fotografia, dança, teatro, entre outras (BRASIL, 2009).

Para compreender melhor a importância das brincadeiras e interações na educação infantil, cabe frisar que os estudos desenvolvidos por Vygotsky identificaram que o homem não nasce humano. Dessa forma, o homem se tornará humano no decorrer do processo de apropriação de conhecimentos, por meio da cultura e da história, à medida que intervém na sociedade. É na interação com o outro e com os objetos criados, que o homem se humaniza e cria sua individualidade.

Diante o exposto, a criança é capaz de reproduzir aptidões e habilidades humanas que estão incorporadas nos costumes, valores, gestos, linguagens, códigos, brincadeiras e objetos existentes. Daí a importância dos professores de educação infantil possibilitarem o acesso às experiências e à cultura da sociedade (MELLO, 1999).

Nesse entendimento, cabe elucidar que:

$\mathrm{Na}$ história cotidiana das interações com diferentes parceiros vão sendo construídas significações compartilhadas a partir das quais as crianças aprendem como agir ou mesmo resistir aos valores e normas da sua cultura. Nesse processo é preciso considerar que elas aprendem coisas que lhes são muito significativas quando interagem com companheiros da infância, e que são diversas das coisas que elas se apropriam no contato com os adultos ou com crianças mais velhas. Além disso, à medida que o grupo de crianças interage, são construídas as culturas infantis (Parecer CNE/CEB, 2009, p. 7).

A partir das brincadeiras e interações que as crianças estabelecem com as outras de menor ou maior idade, com os professores, com a coordenadora pedagógica, com as gestoras da escola, com os pais, com os familiares e com os demais participantes deste processo de aprendizagem, é 
que elas produzem conhecimento e desenvolvem habilidades humanas. Neste sentido, "a leitura do corpo nada mais é do que um processo de conscientização, da afirmação da personalidade, da individualidade, do sentido de pertença à etnia humana" (NISTA-PICCOLO; MOREIRA, 2012, p. $50)$.

Nessa perspectiva, a corporeidade surge como uma abordagem importante para a prática docente das professoras de educação infantil, pois compreende que a educação de crianças é humanizadora e permite o acesso à aprendizagem e à internalização das qualidades humanas, a partir da ampliação de significados, possibilitando o desenvolvimento do ser. Logo, segundo NistaPiccolo e Moreira (2012) "ter o sentido de corporeidade como princípio para o trabalho na Educação Infantil é recuperar o compromisso da elevação da concepção de humanidade” (p. 53-54).

Conforme os autores, o trabalho docente deve preocupar-se com a criatividade e a imaginação, elementos muito presentes nas atividades desenvolvidas pelas crianças. Destaca-se que a motricidade das crianças propiciada por meio da prática docente permite a liberdade da ação, imaginação e criação com a diversidade de brincadeiras, contação de histórias, sugestão e alteração nas regras do jogo, busca de resoluções de conflitos, ambiente de motivação e concentração entre os pares, realização das vontades, respeito e cooperação.

Considerando os relatos realizados pelas professoras, percebe-se que elas atribuem um papel importante às brincadeiras, danças, jogos e passeios com as crianças pelos espaços da escola, e ainda relacionam estas práticas com a corporeidade. Ressalta-se que as atividades precisam ser criativas e atrativas, propiciando às crianças momentos de imaginação, criatividade e interação.

Entretanto, o que se percebeu durante as observações é que a maioria das atividades realizadas pelas professoras é relacionada ao cumprimento dos deveres de registro em sala. Por exemplo, as professoras P1PARTC, P2PARTC, P5PARTP e P6PARTP precisam cumprir juntamente com as crianças as tarefas do livro didático, vale ressaltar que esta ação ocorre exclusivamente durante o tempo de aula da turma, pois, devido à rotina, os demais momentos são destinados para as atividades extraclasses, realizadas por professores contratados, como por exemplo, balé, capoeira, música, ensino religioso, educação física, inglês, entre outros. Logo, é evidente a necessidade da professora da turma de gerir e explorar mais o tempo das aulas com atividades que não se restrinjam ao livro didático, mas também com outras que permitam às crianças a se relacionarem de forma mais autônoma e coletiva.

É importante reforçar a ideia de que a professora de educação infantil deve ser formada em Pedagogia para que realize um trabalho docente focado em contemplar o desenvolvimento integral 
da criança, enquanto ser global, ativo, individual, coletivo e complexo, sem fragmentações na aprendizagem. A própria professora da turma pode desenvolver as atividades consideradas extras, no entanto, deve ter formação específica para que possibilite a compreensão de que a criança é um ser em movimento que necessita vivenciar e compartilhar experiências.

Destaca-se que o professor de educação física pode adentrar na educação infantil, no sentido de contribuir para a formação do professor desta etapa da educação, a partir da ampliação do repertório de atividades, bem como, da colaboração teórica para a prática docente, relacionada às atividades com a corporeidade das crianças.

Quanto às outras professoras, percebeu-se que a maioria das práticas docentes das P3PUBLC, P4PUBLC, P7PUBLP e P8PUBLP são voltadas às atividades livres, sem uma relação de mediação professora-criança. Por exemplo, as professoras disponibilizaram as crianças os brinquedos doados pelos pais, muitos estão deteriorados, e as crianças demonstraram descontentamento em brincar com aquele mesmo brinquedo. Assim, percebeu-se que falta intencionalidade no ato de educar. Estes momentos poderiam ser dedicados à realização de atividades dirigidas nos espaços das escolas, com inovação, significado e criatividade, para aguçar nas crianças a vontade de brincar, criar e imaginar, por meio das relações corporais interagindo com os outros.

Na sequência, evidencia-se de forma mais detalhada a prática docente de cada professora participante desta pesquisa.

As participantes P1PARTC e P2PARTC desenvolvem as mesmas atividades durante a semana. Ambas executam as tarefas do livro didático com as crianças. Percebeu-se que as atividades restringiram-se ao conhecimento de cores, formas geométricas, pontilhados, identificação e colagem de letras e números isolados no caderno. Durante as atividades, as professoras solicitam aos infantes que permaneçam em silêncio dentro da sala. Destaca-se que a escrita deve-se remeter ao mundo real e com sentido para as crianças, para que o conhecimento seja apreendido em sua totalidade. O trabalho com letras soltas não expressam significados para as crianças (MELLO, 2012).

Entende-se que a criança aprende na perspectiva do corpo em sua totalidade, a corporeidade e a motricidade estão intimamente relacionadas neste processo. Dessa forma, o movimento não se relaciona ao desenvolvimento de atividades repetitivas, mas implica na capacidade de criar, pensar, agir, imaginar, enfrentar as dificuldades, atribuir significados e tomar consciência do movimento (PROSCÊNCIO, 2010). 
No que diz respeito à ação docente das P3PUBLC e P4PUBLC, evidenciou-se a existência de práticas de imposição de silêncio, pequenos castigos e ameaças, como por exemplo, as professoras colocam as crianças que não se comportam no canto da sala, para "refletirem" o que fizeram de errado. Ambas enfatizam que as crianças que não se comportarem ficarão no quintal junto com o jardineiro. Destaca-se que as crianças demonstram medo deste funcionário em decorrência dessa intimidação.

De acordo com Inforsato (2006), ao longo da história, professores, acreditando estar propiciando um maior conhecimento às crianças, buscavam educar o corpo com ênfase nos aspectos cognitivos. Formou-se o consenso de que a função da escola é o de preparar os sujeitos à disciplina do trabalho organizado.

Observou-se que a atuação da professora P5PARTP é bem metódica, ela segue o que está no plano, esforçando-se para que o tempo seja suficiente para cumprir todas as tarefas do livro didático. A turma é muito silenciosa, as cadeiras ficam dispostas uma atrás das outras. Ressalta-se que a professora dinamiza da melhor forma o que está posto no livro, contudo as atividades restringem-se a isso.

Enquanto que a professora P6PARTP oportuniza momentos para que as crianças dialoguem, experimentem, movimentem e interajam com as outras crianças. Embora a professora desenvolva tarefas do livro didático com as crianças, ela procura diversificar as atividades dentro e fora da sala de atividades. E quando percebe que as crianças estão cansando, convida-as para passear na área externa da escola. Nessa perspectiva, "a corporeidade tem um papel imprescindível como canalizador das percepções culturais, manifestadas através dos próprios sentidos, entendidas assim como experiências de ser no mundo" (COUTO, 2008, p. 28).

Por fim, as atividades desenvolvidas pelas professoras P7PUBLP e P8PUBLP pautam-se em pintura de desenhos prontos, músicas, contação de histórias e brincadeiras livres. Percebeu-se que estas atividades, propostas pelas professoras, são pouco atrativas para as crianças, com precárias possibilidades de criação e imaginação.

Diante o exposto, é importante mencionar que as atividades realizadas na educação infantil deveriam caracterizar-se por momentos de afetividade, sensibilidade, imaginação, criatividade e emoção. É nesses espaços que a corporeidade se manifesta, criando e se recriando, a partir da intencionalidade da professora ao possibilitar momentos importantes para o desenvolvimento infantil. 
Portanto, das práticas docentes observadas nesta pesquisa, verifica-se que a corporeidade se manifesta nas atividades propostas pela P6PARTP, evidenciando o corpo sujeito que se constrói nas relações estabelecidas com o outro, objetos e com o mundo, a partir da promoção de vivências, produzindo o aprendizado e o desenvolvimento integral da criança.

Quanto às demais participantes desse estudo, observa-se que as atividades propostas não estão embasadas pelos pressupostos da corporeidade, pois as práticas docentes são realizadas de forma individual, célere e fragmentadas, uma vez que são desenvolvidas, na maioria das vezes, com a ausência da relação professora-criança, sem tempo suficiente para a concretização de determinada tarefa e compartilhamento de ideias entre os infantes, pois, geralmente, sentam-se juntos, mas as atividades são separadas. Estas práticas interferem no desenvolvimento infantil, inviabilizando vivências e experiências importantes para o aprendizado.

Defende-se neste estudo a seguinte compreensão:

O corpo é do ponto de vista científico, a instância fundamental e básica para articular conceitos centrais para uma teoria pedagógica. Em outras palavras: somente uma teoria da corporeidade pode fornecer as bases para uma teoria pedagógica (ASSMANN, 1995, p. 113).

Deste modo, as professoras de educação infantil que realizam as práticas docentes pautandose na temática da corporeidade estarão intencionalmente desenvolvendo valores relacionados a autonomia, espontaneidade, criatividade, imaginação, cooperação, respeito, solidariedade, considerados fundamentais para uma educação humanizadora, entendida como essencial para o desenvolvimento infantil.

\section{CONSIDERAÇÕES FINAIS}

As instituições de educação infantil, bem como, a família e os espaços de interações sociais, formam o contexto de desenvolvimento humano. Logo, a partir das vivências e experiências é que o sujeito produz conhecimento, sendo capaz de conhecer as diferenças existentes entre as pessoas, por conseguinte, aprendendo a respeitá-las.

A educação infantil é uma etapa da educação básica que possibilita à criança ampliar seu repertório de informações e relações sociais. E nesse processo de aprendizado, precisa reconhecerse como sujeito ativo, a partir da compreensão do seu próprio corpo, dos outros seres, dos objetos e do mundo. Portanto, a ação docente deve estar voltada, primeiramente, à formação da criança, enquanto ser autônomo, reflexivo, atuante e crítico. 
Ao realizar o aprofundamento teórico deste estudo percebeu-se que os processos de formação de professores devem contemplar teorias e práticas que fundamentem o pensar e o agir docente voltadas à compreensão do ser humano integral, social, complexo, histórico e cultural. Nesse aspecto, a corporeidade surge como uma abordagem importante para fomentar a atuação profissional, pois busca conhecer o fenômeno humano a partir do sentido da existência, da sensibilidade, da imaginação, das experiências, das vivências e da aprendizagem significativa.

Cabe observar que as práticas docentes são constituídas por diversos saberes, provenientes das instituições de ensino superior, dos currículos, da vida cotidiana e das formações profissionais iniciais e continuadas. Portanto, torna-se fundamental que os professores de educação infantil mantenham-se em constante aprendizado, considerando o fluxo de informações, transformações na própria ação e a complexidade que envolve a atividade de ensinar.

Conclui-se nesta pesquisa que as práticas docentes das professoras de educação infantil devem ser norteadas pela corporeidade, para isso é imprescindível que se percebam como sujeitos capazes de compreender o mundo por meio de suas vivências e de saberes acumulados historicamente, investindo também em formação continuada que lhes possibilite mais conhecimentos para agirem intencionalmente, fomentando o desenvolvimento integral das crianças, permitindo a elas a autoria de fazerem escolhas sem restringir a autonomia, pensamentos, ações, tempo e espaço, elementos estes necessários para o conhecimento das coisas, dos seres, do mundo e de tudo que possa circundá-lo. 


\section{REFERÊNCIAS}

ABRANTES, A.A.; MARTINS, L.M.A produção do conhecimento científico: relação sujeito-objeto e desenvolvimento do pensamento. Interface - Comunic, Saúde, Educ., v. 11, n. 22, p. 313-25, maio/ago. 2007. Disponível em: <http://www.scielo.br/pdf/icse/v11n22/10.pdf>. Acesso em: 15 jan. 2019.

ASSMANN, H. Paradigmas educacionais e corporeidade. 3. ed. Piracicaba: Unimep, 1995.

BARDIN, L. Análise de Conteúdo. São Paulo: Edições 70, 2011.

BORBA, A. M. Brincadeira como experiência de cultura na educação infantil. In: BRASIL/MEC - Revista Criança do professor de educação infantil, Brasília: Ministério da Educação, Secretaria de Educação Básica, 2007.

BRASIL. Resolução 05/2009. Diretrizes curriculares nacionais para a educação infantil. Diário Oficial da União. Brasília: MEC/CEB, 10 dez. 2009, Seção 1.

COUTO, H. R. F. A criança e as manifestações lúdicas de rua e suas relações com a educação física escolar. Piracicaba, 2008. 131 p. Dissertação (Mestrado em Educação Física). Núcleo de Pedagogia do Movimento, Corporeidade e Lazer, Universidade Metodista de Piracicaba. Disponível em: <https://www.unimep.br/phpg/ bibdig/pdfs/2006/UWRIFYTSWRJB.pdf>. Acesso em: 15 jan. 2019.

FREIRE, P. Pedagogia da autonomia: saberes necessários à prática educativa. São Paulo, Paz e Terra, 2011.

INFORSATO, C.F.; FIORANTE, F.B. Corporeidade: por uma abordagem humanizadora do corpo em busca da existencialidade. Revista Mackenzie de Educação Física e Esporte, 9 (2): 135-144, 2010.

INFORSATO, E. A educação entre o controle e a libertação do Corpo. In: MOREIRA, Wagner Wey. (Org.). Século XXI: a era do corpo ativo, Campinas: Papirus, 2006. p. 91-108.

LEONTIEV, A. O desenvolvimento do psiquismo. Lisboa: Horizonte, 1978.

MELLO, S. A. Algumas implicações pedagógicas da Escola de Vygotsky para a educação infantil. Pro-Poslções, vol. 10, n. 1 (28), mar. 1999. Disponível em: <http://geplei.sites.ufms.br/files/2015/10/algumas-implica\%C3\%A7\% C3\%B5es-pedag\%C3\%B3gicas-da-escola-de-Vyg.pdf >. Acesso em: 25 jan.2019.

Uma teoria para orientar o pensar e o agir docentes: o enfoque histórico-cultural na prática da educação infantil. In: CHAVES, Marta. (Org.). Intervenções Pedagógicas e Educação Infantil. Maringá/PR: Eduem, 2012. v. 1, p. 19-36.

MERleAU-PONTY. M. Fenomenologia da Percepção. 2. ed. São Paulo: Martins Fontes, 1999. Disponível em: <http://monoskop.org/images/0/07/Merleau_Ponty_Maurice_Fenomenologia_da_percep\%C3\%A7\%C3\%A3o_1999.pd f>. Acesso em: 30 jan. 2019.

MINAYO, M. C. de S. O Desafio do Conhecimento: Pesquisa Qualitativa em Saúde. 10. ed. São Paulo: HUCITEC, 2007. $406 \mathrm{p}$.

MOREIRA, W. W. et al. Corporeidade aprendente: a complexidade do aprender viver. In: MOREIRA, Wagner Wey. (Org.). Século XXI: a era do corpo ativo. Campinas: Papirus, 2006.

NISTA-PICCOLO, V.L.; MOREIRA, W.W. Corpo em movimento na educação infantil. São Paulo: Cortez, 2012.

PROSCÊNCIO, P. A. Concepção de corporeidade de professores da educação infantil e sua ação docente. 2010. 149f. Dissertação (Mestrado) - Programa de Mestrado em Educação, Universidade Estadual de Londrina, Londrina, PR, 2010.

RODRIGUES, N. Educação: da formação humana à construção do sujeito ético. Educação e Sociedade, Campinas, ano XXII, n. 76, p. 232-257, out. 2001.

RODRIGUES, R. B. Corporeidade e educação no campo: os sentidos atribuídos ao corpo na prática docente nos territórios rurais de Santarém-PA, 2018. 142 fl. Dissertação (Mestrado em Educação) - Programa de pós-graduação em educação, Universidade Federal do Oeste do Pará. 


\section{RESUMO}

Este estudo teve como objeto investigar a ação docente na educação infantil à luz da corporeidade, com professoras de escolas públicas e particulares de Santarém - Pará. Desenvolveu-se uma pesquisa de campo, com uma abordagem qualitativa. As técnicas utilizadas foram: observação não participante e entrevista semiestruturada com 08 professoras da educação infantil. Os resultados permitem concluir que as práticas docentes de 07 participantes não estão em conformidade com o que se constata nas produções teóricas realizadas, refletindo assim na promoção de ações reproduzidas. Desta forma, torna-se fundamental que os professores de educação infantil se mantenham em constante aprendizado, considerando a complexidade que envolve a atividade de ensinar.

Palavras-chave: Ação Docente. Corporeidade. Educação Infantil.

\section{THE TEACHING ACTION IN CHILDREN EDUCATION IN THE LIGHT OF CORPOREITY}

\section{ABSTRACT}

The objective of this study was to investigate the teaching activity in children 's education in the light of corporeity, with teachers from public and private schools in Santarém - Pará. A field research was developed with a qualitative approach. The techniques used were: non-participant observation and semi-structured interview with 08 teachers of early childhood education. The results allow to conclude that the teaching practices of 07 participants are not in accordance with what is verified in the theoretical productions made, thus reflecting in the promotion of actions reproduced. In this way, it is fundamental that the teachers of early childhood education keep in constant learning, considering the complexity that involves the activity of teaching.

Keywords: Teaching action. Corporeity. Child education.

\section{LA ACCIÓN DOCENTE EN LA EDUCACIÓN INFANTIL A LA LUZ DE LA CORPOREIDAD}

\section{RESUMEN}

Este estudio tuvo como objeto investigar la acción docente en la educación infantil a la luz de la corporeidad, con profesoras de escuelas públicas y particulares de Santarém - Pará. Se desarrolló una investigación de campo, con un abordaje cualitativo. Las técnicas utilizadas fueron: observación no participante y entrevista semiestructurada con 08 profesoras de la educación infantil. Los resultados permiten concluir que las prácticas docentes de 07 participantes no están en conformidad con lo que se constata en las producciones teóricas realizadas, reflejando así en la promoción de acciones reproducidas. De esta forma, se vuelve fundamental que los profesores de educación infantil se mantengan en constante aprendizaje, considerando la complejidad que implica la actividad de enseñar.

Palabras clave: Acción Docente. Corporeidad. Educación Infantil.

Submetido em 30 de julho de 2019 Aprovado em 01 de setembro de 2019 